\title{
Influence of feeding artificial-formula milks containing docosahexaenoic and arachidonic acids on the postnatal long-chain polyunsaturated fatty acid status of healthy preterm infants
}

\author{
BY MAGRITHA M. H. P. FOREMAN-VAN DRONGELEN ${ }^{1}$, \\ ADRIANA C. VAN HOUWELINGEN ${ }^{1 *}$, ARNOLD D. M. KESTER ${ }^{2}$, \\ CARLOS E. BLANCO ${ }^{3}$, TOM H. M. HASAART ${ }^{4}$ AND GERARD HORNSTRA ${ }^{1}$ \\ Departments of ${ }^{1}$ Human Biology and ${ }^{2}$ Methodology and Statistics, University of Limburg, \\ Universiteitssingel 50, 6229 ER Maastricht, The Netherlands \\ Departments of ${ }^{3}$ Neonatology and ${ }^{4}$ Obstetrics and Gynaecology, University Hospital Maastricht, \\ P Debyelaan 25, 6229 MX Maastricht, The Netherlands
}

(Received 16 October 1995 -Revised 14 February 1996-Accepted 4 March 1996)

\begin{abstract}
In view of the importance of long-chain polyunsaturated fatty acids (LCP) for growth and development of fetal and infant neural tissue, the influence of the dietary $n-3$ and $n-6$ LCP intake on the LCP status of forty-three preterm infants (birth weight $<1800 \mathrm{~g}$ ) was studied. Thirty-one formula-fed infants were randomly assigned to receive a conventional formula lacking LCP ( $n$ 16), or an 22:6n-3- and 20:4n-6enriched formula $(n$ 15); twelve infants received their own mother's breast milk. Fatty acid compositions of plasma and erythrocyte (RBC) phospholipids (PL) were determined in umbilical venous blood, in weekly postnatal samples until day 35 of life and, for the formula-fed infants, at 3 months of corrected age. Both in plasma $(P<0.001)$ and $\operatorname{RBC}(P<0.01)$ PL, the changes with time until day 35 for 22: $6 n-3$ and $20: 4 n-6$ in the two groups of formula-fed infants were significantly different, with higher values, comparable with those of human-milk-fed infants, in the LCP-enriched-formula group. At 3 months of corrected age, differences between the two formula-fed groups were even more pronounced. In conclusion, adding $22: 6 n-3$ and $20: 4 n-6$ to artificial formulas in balanced ratios and in amounts similar to those found in preterm human milk raises both the $22: 6 n-3$ and the $20: 4 n-6$ status of formulafed preterm infants to values found for human-milk-fed preterm infants. Additional studies are necessary to evaluate the potentially favourable effects of this combined addition on the neurodevelopmental outcome of preterm infants.
\end{abstract}

Docosahexaenoic acid: Arachidonic acid: Preterm infant: Human milk: Artificial-formula milk

Long-chain polyunsaturated fatty acids (LCP; polyunsaturated fatty acids with a chain length of $\mathrm{C}_{20}$ or more, and derived from the parent essential fatty acids (EFA) linoleic acid $(18: 2 n-6)$ and $\alpha$-linolenic acid $(18: 3 n-3)$ through alternate desaturation and elongation), docosahexaenoic acid (cervonic acid; $22: 6 n-3)$ and arachidonic acid $(20: 4 n-6)$ in particular, are the predominant structural fatty acids in the human brain (Svennerholm, 1968; Martinez et al. 1974; Sastry, 1985) and retina (Fliesler \& Anderson, 1983). These LCP accumulate rapidly in fetal and infant neural tissue during the periods of most rapid growth and development, that is during the last months of gestation and the first months of postnatal life (Clandinin et al. 1980a, b; Martinez et al. 1988; Martinez, 1992; Makrides et al. 1994).

Unlike term infants, preterm infants cannot benefit from the maternal and placental 
LCP supply during the last trimester of pregnancy to cover the demands associated with this LCP accretion. Instead, they are dependent on their own dietary supply through either human milk, which contains small but significant amounts of $22: 6 n-3,20: 4 n-6$ and other LCP, or through commercially-available artificial-formula milks, the majority of which do not contain more than trace amounts of LCP (Jensen et al. 1978, 1992; Lammi-Keefe \& Jensen, 1984). A substantial number of studies in preterm populations have since demonstrated that these conventional formulas, even when they do contain substantial amounts of the parent EFA, linoleic acid $(18: 2 n-6)$ and $\alpha$-linolenic acid $(18: 3 n-3)$, are unable to maintain postnatal $22: 6 n-3$ and $20: 4 n-6$ levels in plasma and erythrocyte (RBC) lipids at levels observed after feeding human milk (Carlson et al. 1986 a; Pita et al. 1988; Koletzko et al. 1989; Clandinin et al. 1992; Foreman-van Drongelen et al. 1995a). Probably, the desaturase capacity of preterm newborns is too limited to cover adequately the demands for $n-3$ and $n-6$ LCP only through metabolic conversion of the two parent fatty acids (Clandinin et al. 1981 $a$; Chambaz et al. 1985). In addition, preterm newborn infants have very limited fatty acid stores (Clandinin et al. 1981a,b).

These observations have prompted an increasing number of attempts, with varying degrees of success, to reduce the differences between the biochemical LCP status of humanmilk-fed and formula-fed infants by adding LCP to the diets of the latter (Carlson et al. 1987, 1991; Liu et al. 1987; Koletzko et al. 1989; Clandinin et al. 1992; Hoffman \& Uauy, 1992; Carnielli et al. 1994). However, increasing only the dietary $n$-3 LCP intake, through the addition of marine oils, resulted not only in the desired enhancement of $22: 6 n-3$ levels, but also in decreased 20:4n-6 levels (Carlson et al. 1991; Hoffman \& Uauy, 1992), and has been reported to be associated with diminished first-year growth rates (Carlson et al. 1992a, 1993 a). The effects of formulas containing both $n-3$ and $n-6$ LCP on LCP status have also been reported (Koletzko et al. 1989; Clandinin et al. 1992; Carnielli et al. 1994), but the duration of supplementation in these studies was confined to a few weeks.

We, therefore, studied the effects of long-term feeding of artificial formulas, containing both 22:6n-3 and 20:4n-6 in amounts present in human milk, in formula-fed preterm infants which were randomly assigned to receive either a conventional artificial formula or the LCP-enriched formula. The LCP patterns of both plasma and RBC phospholipids (PL) were studied until 3 months after the initially expected date of delivery. The PL fraction was studied because PL are structural lipids, which are the richest source of polyunsaturated fatty acids (PUFA), including LCP, and because changes in PUFA profile are most pronounced in PL (Holman, 1986). Values for 22:6n-3 and 20:4n-6 during the first 5 weeks of life of infants fed on the supplemented formulas were compared with those of a group of preterm infants raised on their own mother's breast milk.

\section{SUBJECTS AND METHODS}

\section{Experimental design}

Subjects. The total population comprised forty-three infants (birth weight 900-1795 g), who were born before the 37 th week of gestation, had a birth weight appropriate for gestational age (above the 2.3 percentile of the Amsterdam growth charts; Kloosterman, 1970), and were free from metabolic disease and major congenital malformations. Gestational age was confirmed by menstrual history and early ultrasound dating, and by Dubowitz score (Dubowitz et al. 1970) if the former information was missing or doubtful. Only infants with a birth weight of $1800 \mathrm{~g}$ or less were included, because larger infants were likely to be discharged home before the intended minimum duration of the study (4 weeks). Immediately after delivery (day 0), approximately $3 \mathrm{ml}$ umbilical venous blood was collected. Thereafter, the EFA status of the infants was monitored until discharge home or 
transfer to a non-participating hospital. For this purpose, a weekly sample of approximately $0.5 \mathrm{ml}$ capillary or venous blood was collected in conjunction with a diagnostic puncture, which was part of the routine clinical monitoring at the neonatology ward. Because of the frequent oral feeds that are given to preterm infants (every $2-3 \mathrm{~h}$ ), blood samples could not be collected after fasting, but were taken between 1 and $1.5 \mathrm{~h}$ after a feed. For the formulafed infants, follow-up was extended after discharge to 3 months after the initially expected date of delivery ( 3 months of corrected age), when a final blood sample was collected.

All infants were admitted to the neonatal care unit, where clinical care was provided by the attending neonatologists and resident physicians, according to current standards.

Some infants received intravenous $\mathrm{RBC}$ and plasma infusions at different times during the treatment. Since these preparations contain significant amounts of $22: 6 n-3$ and $20: 4 n-6$, the time of infusion and the amount administered were recorded carefully. Furthermore, neonatal blood samples were always collected $24 \mathrm{~h}$ or more after an infusion. The infants were discharged home when their weight reached $2400 \mathrm{~g}$.

The study was approved by the Medical Ethics Committees of the participating hospitals, and written informed consent was obtained from one or both parents.

Diets. Infants were eligible to enter the study when they were able to tolerate enteral feedings and no longer required respiratory support (continuous positive airway pressure or intubation and mechanical ventilation). If the mother did not wish to provide breast milk, her infant was introduced to enteral feeding with a premature-infant formula. These infants were randomly assigned to receive either a commercially-available, conventional artificial-formula milk, containing no LCP (preterm C-AF), or an LCP-enriched version of this formula, containing $22: 6 n-3$ and $20: 4 n-6$ in balanced ratios $(1: 2)$ and in amounts approximating those in human milk (preterm LCP-AF; see Table 1). The sources of the LCP were highly purified 'single-cell oils', which are produced by single-celled organisms, such as micro-algal and fungi. The LCP were added to the formula during commercial processing. Appropriate precautions against oxidation were taken during processing and storage, including the addition of $30 \mathrm{mg} \alpha$-tocopherol/1 LCP-enriched formula.

Double-blind randomization was performed using a computerized randomization program, and resulted in sixteen infants being fed on the conventional formula and fifteen receiving the LCP-enriched formula. At a weight of $2000 \mathrm{~g}$ the conventional prematureinfant formula was replaced by a commercially-available conventional regular infant formula, again containing no LCP (term C-AF), while the LCP-enriched preterm formula was replaced by an LCP-enriched, but otherwise identical, term formula (term LCP-AF; see Table 1). After the participating infants were discharged from the hospital, their parents were provided free of charge with ample supplies of these term formulas for use at home. The formulas were supplied as ready-to-use bottles of $60 \mathrm{ml}$ (preterm formulas) or 100 and $200 \mathrm{ml}$ (term formulas). To ensure an optimal patient compliance during hospitalization, the volumes of formula given and the numbers of the bottles used were recorded carefully by the nursing personnel. At home, the parents were instructed to fill in a daily questionnaire on the volumes of study formula, as well as any additional foods, consumed by their infants. In addition, the parents were counselled regularly.

For comparison with the LCP-enriched-formula-fed infants, a further twelve infants given (initially expressed) preterm human milk obtained from their own mothers (for average fatty acid composition, see Table 1) were studied. In five of these twelve infants a breast milk fortifier was added to the milk expressed by their mothers. This fat-free fortifier was introduced on the neonatology ward halfway through our study and served to bring the intake of protein, vitamins, and minerals of human-milk-fed preterm infants in line with their needs for these nutrients. It enhanced the energy intake content of the human milk by $440 \mathrm{~kJ} / 1$. When the mother was unable to express enough milk, an appropriate formula 
Table 1. Fatty acid composition ( $\mathrm{mg} / 100 \mathrm{mg}$ total fatty acids) of total lipids of preterm human milk $(H M)$ and of the conventional $(C-A F)$ and long-chain polyunsaturated fatty acid ( $L C P$ )-enriched (LCP-AF) artificial-formula milks used*

(For human milk, values are medians and interquartile ranges of the average content during the study period (days 0-35)

\begin{tabular}{|c|c|c|c|c|c|c|}
\hline \multirow{2}{*}{$\begin{array}{l}\text { Fatty acid } \\
(\mathrm{mg} / 100 \mathrm{mg})\end{array}$} & \multicolumn{2}{|c|}{$\begin{array}{c}\text { Preterm } \\
\text { formula milk }\end{array}$} & \multicolumn{2}{|c|}{$\begin{array}{c}\text { Term } \\
\text { formula milk }\end{array}$} & \multicolumn{2}{|c|}{$\begin{array}{l}\text { Preterm HM } \\
(n 6)\end{array}$} \\
\hline & $\mathrm{C}-\mathrm{AF}$ & LCP-AF & $\mathrm{C}-\mathrm{AF}$ & LCP-AF & Median & Range \\
\hline$\Sigma$ SAFA $\dagger$ & $39 \cdot 5$ & $38 \cdot 5$ & $41 \cdot 1$ & $40 \cdot 4$ & $48 \cdot 1$ & $43 \cdot 4-50 \cdot 3$ \\
\hline$\Sigma$ MUFA $†$ & $44 \cdot 3$ & $44 \cdot 6$ & $44 \cdot 3$ & 44.9 & $32 \cdot 4$ & $30 \cdot 9-36 \cdot 1$ \\
\hline$\Sigma$ PUFA $\dagger$ & $15 \cdot 5$ & $16 \cdot 4$ & $14 \cdot 2$ & $14 \cdot 1$ & $18 \cdot 7$ & $14 \cdot 6-21 \cdot 7$ \\
\hline $18: 2 n-6$ & $14 \cdot 3$ & $14 \cdot 3$ & $12 \cdot 8$ & $12 \cdot 0$ & $14 \cdot 7$ & $11 \cdot 3-18 \cdot 1$ \\
\hline $20: 3 n-6$ & ND & 0.06 & ND & 0.05 & 0.55 & $0.49-0.63$ \\
\hline $20: 4 n-6$ & ND & 0.61 & $\mathrm{ND}$ & 0.54 & 0.52 & $0.43-0.64$ \\
\hline$\Sigma n-6 \mathrm{LCP} \dagger$ & ND & 0.67 & ND & 0.59 & $1 \cdot 26$ & $1.04-1 \cdot 48$ \\
\hline $18: 3 n-3$ & $1 \cdot 2$ & $1 \cdot 1$ & 1.4 & $1 \cdot 2$ & 0.90 & $0.77-1.02$ \\
\hline $20: 5 n-3$ & ND & ND & ND & ND & 0.04 & $0.04-0.06$ \\
\hline $22: 6 n-3$ & ND & $0 \cdot 30$ & ND & 0.30 & 0.26 & $0.22-0.42$ \\
\hline$\Sigma n-3 \mathrm{LCP}+$ & ND & $0 \cdot 30$ & ND & $0 \cdot 30$ & 0.57 & $0.48-0.80$ \\
\hline
\end{tabular}

$\Sigma$ SAFA, sum of saturated fatty acids; $\Sigma$ MUFA, sum of monounsaturated fatty acids; $\Sigma n-6 \mathrm{LCP}$, sum of $n-6$ LCP $(20: 3 n-6,20: 4 n-6,22: 4 n-6$, and $22: 5 n-6) ; \Sigma n-3$ LCP, sum of $n-3$ LCP $(20: 4 n-3,20: 5 n-3,22: 5 n-3$ and $22: 6 n-3) ; \mathrm{ND}$, not detected.

* For artificial formulas, data are based on chemical analyses performed at the Nutricia Chemical and Physical Research Laboratory Zoetermeer, The Netherlands; for human milk, results are based on our own analyses as described previously (Foreman-van Drongelen et al. 1995a).

$\dagger$ Measurements were made for individual fatty acids but these are not shown.

(preterm conventional artificial formula; Table 1) was supplied to cover the nutritional demand of her child. If the intake of artificial formula exceeded $250 \mathrm{ml} / 1$ total enteral intake, the infant was no longer included in the human-milk group.

Enteral feedings were administered through a nasal tube, until the infant was able to drink from a bottle or his or her mother's breast. Until the infants were on full enteral feeding they received parenteral nutrition, containing the appropriate amounts of carbohydrates ( $210 \mathrm{~kJ} / \mathrm{kg}$ per d), amino acids $(50 \mathrm{~kJ} / \mathrm{kg}$ per d), vitamins, and minerals. In addition, up to $95 \mathrm{~kJ} / \mathrm{kg}$ per $\mathrm{d}$ of intravenous lipids (Intralipid ${ }^{\mathbb{B}} 10 \%$ and $20 \%$, Vitalipid ${ }^{\mathbb{B}}$ ) were given as a source of fat. Since these preparations proved to contain up to 0.2 and $0.3 \mathrm{mg}$ $22: 6 n-3$ and $20: 4 n-6 / 100 \mathrm{mg}$ respectively (M. M. H. P. Foreman-van Drongelen; unpublished results), the amounts given were recorded.

\section{Laboratory analysis}

Blood samples were collected in EDTA-containing tubes to prevent coagulation. Plasma and RBC samples were prepared and the fatty acid composition of their PL analysed as described previously (Foreman-van Drongelen et al. 1995a), with the following modifications: extraction of total lipids from RBC was done within 1 week after blood sampling, and according to the method of Bligh \& Dyer (1959). At the start of the analysis, approximately $31.0 \mu \mathrm{g}$ 1,2-dinonadecanoyl phosphatidylcholine (PC- $(19: 0)_{2}$ ) was added to every sample as an internal standard to quantify amounts of fatty acid present in the PL fraction of the plasma and RBC. Absolute amounts of fatty acid are expressed as $\mathrm{mg} / \mathrm{l}$ plasma or RBC suspension, relative fatty acid levels as $\mathrm{mg} / 100 \mathrm{mg}$ total fatty acid methyl esters. 
In total, thirty-nine fatty acids were identified on the basis of a standard reference mixture containing most of the fatty acid methyl esters of interest. Since the present study focuses on the $22: 6 n-3$ and $20: 4 n-6$ status, only the following other relevant fatty acids and fatty acid combinations are reported (full data are available on request): $18: 2 n-6$, dihomo$\gamma$-linolenic acid $(20: 3 n-6), 18: 3 n-3$, eicosapentaenoic acid $(20: 5 n-3)$, sum of all saturated fatty acids ( $\Sigma$ SAFA), sum of all monounsaturated fatty acids ( $\Sigma$ MUFA), sum of all polyunsaturated fatty acids ( $\Sigma$ PUFA), sum of all PUFA of the $n-9$ series ( $\Sigma n-9$ PUFA), sum of the LCP of the $n-6$ series $(\Sigma n-6$ LCP), and sum of the LCP of the $n-3$ series $(\Sigma n-3$ LCP). In addition, two indices were calculated to describe the functional $22: 6 n-3$ status. The cervonic acid deficiency index (CADI), defined as 22:5n-6:22:4n-6 (its immediate precursor), was used because a shortage of $22: 6 n-3$ (cervonic acid) is accompanied by an increased conversion of $22: 4 n-6$ to $22: 5 n-6$, resulting in higher CADI values (Holman, 1977; Neuringer et al. 1986). The cervonic acid sufficiency index (CASI), defined as 22:6n$3: 22: 5 n-6$, was calculated, based on the same metabolic principle, leading to a decreased CASI value in case of an 22:6n-3 shortage (Hoffman \& Uauy, 1992).

\section{Data analysis}

Study size calculations. were based on the results of one of our previous studies (Foremanvan Drongelen et al. 1995a) using the exact calculations provided by Systat's Design program (Dallal, 1988). Assuming an $\alpha$ of 0.05 two-sided, a sample size of fifteen infants per formula group was calculated to be ample for demonstrating a significant inter-group difference in 22:6n-3 status (four infants per group resulted in a power of 0.96 ), while for $20: 4 n-6$ a power of 0.77 would be obtained.

Since during the clinical follow-up not all blood samples could be collected at exactly the intended days, fatty acid values were estimated at days $7,14,21,28$ and 35 by linear interpolation between the actual days on which blood had been sampled. Blood samples were usually collected within $2 \mathrm{~d}$ of these reference days, and for the majority of infants, none or only one of the ideally required six samples was missing. Unless mentioned otherwise, all data are presented as median and the upper and lower limits of the interquartile range.

The two LCP of primary interest, $22: 6 n-3$ and $20: 4 n-6$, were analysed most extensively. Values measured at birth and weekly up to 5 weeks postnatal age were evaluated in a repeated-measures ANOVA model (Jennrich \& Schluchter, 1986; Dixon, 1992), with gestational age and its square as covariables. The model gave estimated mean LCP levels at the mean gestational age of $220 \mathrm{~d}$ for each group, at each of the observation times, with correction for missing data. In the same model we tested the difference between the conventional and the LCP-enriched-formula groups at 4 weeks and at 5 weeks of postnatal age. Within the repeated-measures analysis, 22:6n-3 and 20:4n-6 values for the infants raised on LCP-enriched formulas were also compared with those of the human-milk-fed group. Since the postnatal LCP status has been shown to be related to the LCP status at birth (Foreman-van Drongelen et al. 1995b), and assignment to the human milk or the LCP-enriched-artificial-formula groups was not obtained by randomization but resulted from maternal choice, we compared the changes from the initial values at 4 and 5 weeks in the LCP-enriched-formula and human-milk groups using $95 \%$ CI. CI were used here instead of tests, since demonstration of an unequal LCP status was not a study objective. The CI revealed how close the LCP-enriched-formula group was to its 'natural target', the human-milk group. Model assumptions were checked visually in scatterplots, and apparent outliers were examined for their impact on the qualitative results. Values for $22: 6 n-3$ and $20: 4 n-6$ at 3 months of corrected postnatal age were analysed using the two-tailed Mann- 
Whitney test. For all these primary analyses, $P<0.05$ was considered to reflect a significant difference.

For the other fatty acids, two-tailed Mann-Whitney tests were used to compare values for the two formula-fed study groups at day 0 , at day 35 , and at 3 months of corrected age. For this relatively large number of supportive analyses, differences with a significance level of $P \leqslant 0.01$ were regarded as significant.

The volumes of plasma, RBC and intravenous lipids administered in the three groups and continuous clinical variables were compared using the two-tailed Mann-Whitney test. Discrete clinical variables were compared using the chi-square test. Bonferroni correction with a factor 3 for the number of groups compared was used, when applicable.

\section{RESULTS}

Study populations

The most important clinical and nutritional characteristics of the study groups are shown in Table 2. No relevant differences between the two formula-fed study groups were present for any of these features. The majority of the infants received their first enteral intake well within the first week of life and they were on full enteral feeding of $420-500 \mathrm{~kJ} / \mathrm{kg}$ per d at, on average, the 12th day of life. Both during the clinical and the out-patient follow-up periods, the two groups of formula-fed infants achieved similar and adequate weight gains on comparable enteral energy intakes, which were almost exclusively derived from the study formulas. Energy sources other than formula milk were introduced at the same pace in both groups during the third month of corrected age. They consisted of fruits, which are known to contain no more than trace amounts of fat (NEVO Foundation, 1993), and were consumed in limited amounts in addition to the regular formula feeds.

As a result of the entrance restriction placed on birth weight $(<1800 \mathrm{~g})$, the majority of the participating infants completed the initially intended minimum follow-up of twentyeight postnatal days before discharge home. The one exception was the human-milk-fed infants, nearly half of whom were transferred to a non-participating hospital or received less than $750 \mathrm{ml}$ human milk/l intake by the 4 th week of life. However, because for a sufficient number of infants information on blood LCP status was available until the 35 th day of life, the statistical evaluation of the clinical period could reliably be extended to this postnatal age. Nearly all formula-fed infants continued to participate in the study after discharge home; one infant in each group was discharged before the required term study formulas were available, one infant fed on the conventional formulas turned out to have been fed on a non-study term formula from the second month of corrected age onward.

\section{Plasma phospholipids}

From one infant in the conventional-artificial-formula group, three infants in the LCPenriched-formula group, and one child in the human-milk group, no umbilical blood sample was available.

Different patterns of postnatal changes in $22: 6 n-3$ and $20: 4 n-6$ were obtained when the fatty acid values were expressed as $\mathrm{mg} / \mathrm{l}$ plasma or as $\mathrm{mg} / 100 \mathrm{mg}$ total fatty acid methyl esters (Fig. 1). In the conventional-formula-fed group, concentrations (mg/l) of these major LCP progressively decreased from $7(22: 6 n-3)$ or $0(20: 4 n-6) \mathrm{d}$ of postnatal age onwards. In the group of infants fed on an LCP-enriched formula, these LCP again increased after the 14th day of life. This resulted in significantly higher postnatal concentrations in the latter study group (22: $6 n-3$ : day $28 P<0.01$, day $35 P<0.001 ; 20: 4 n-6$ : day $28 P<0.001$, day $35 P<0.0001$ ). At 3 months of corrected age, average absolute $22: 6 n-3$ and $20: 4 n-6$ amounts were respectively more than three and two times higher in the LCP-enrichedformula group than in the conventional-formula group $(P<0.0001$ for both). Relative 

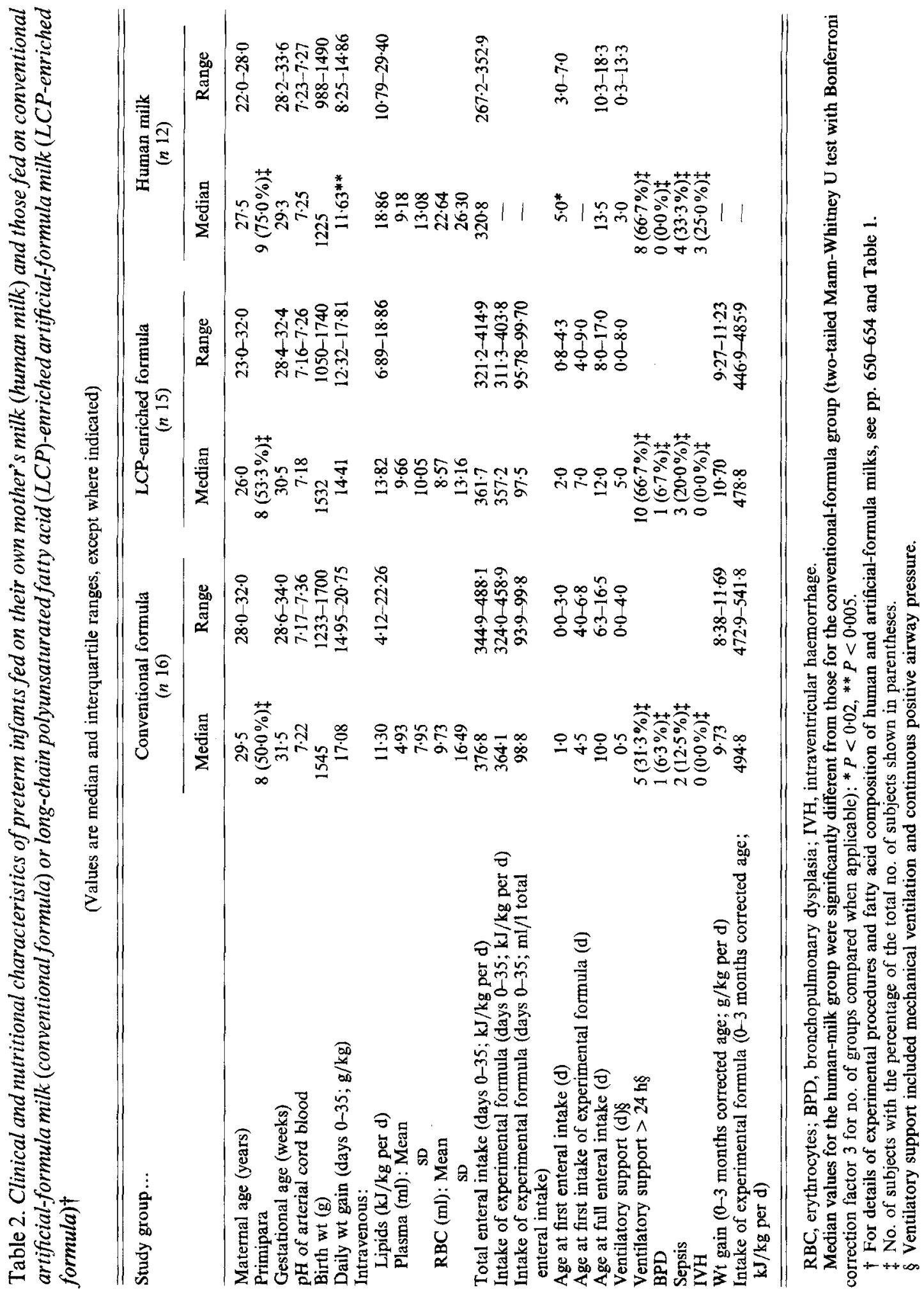

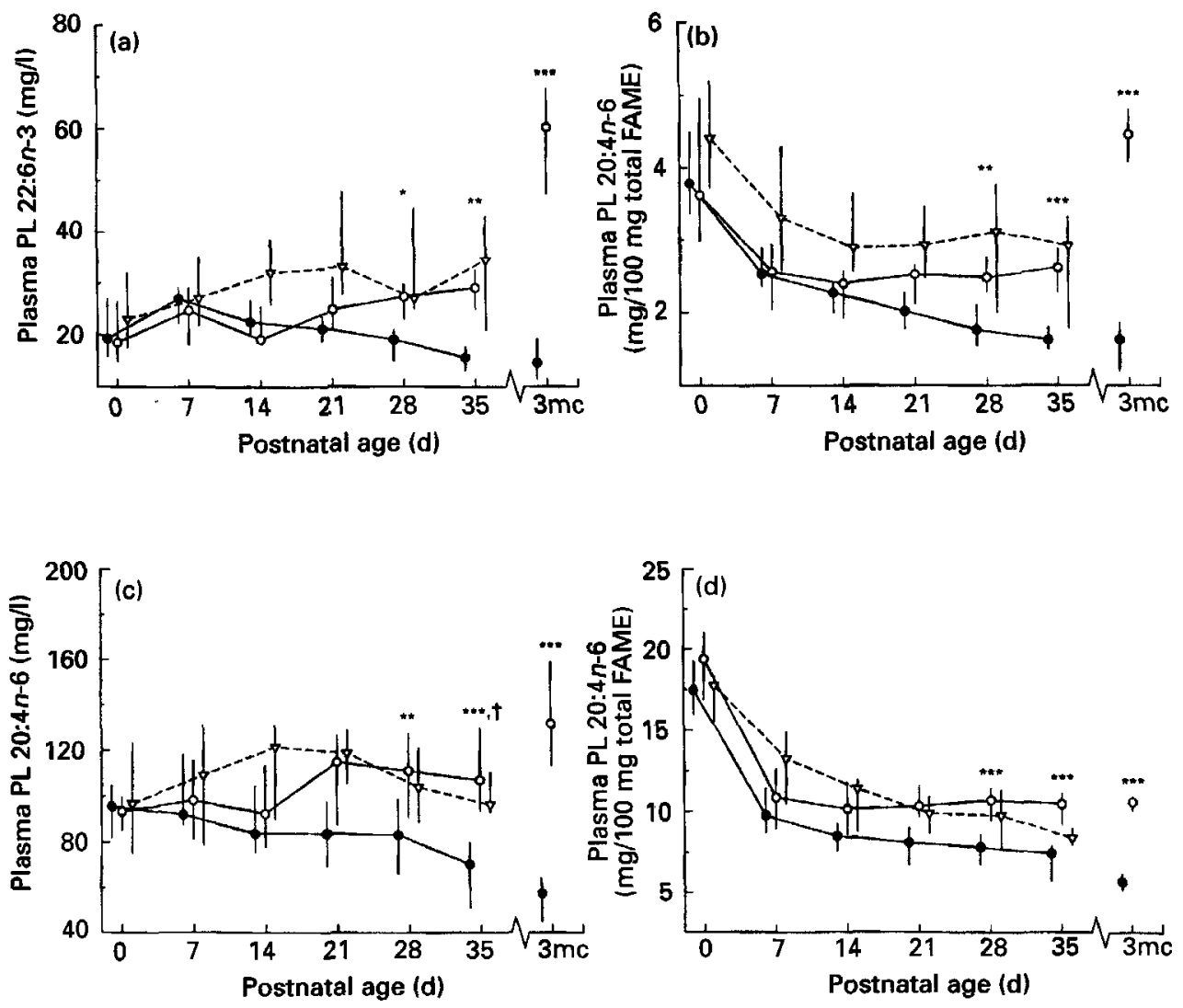

Fig. 1. Fatty acid $22: 6 n-3$ and $20: 4 n-6$ levels in plasma phospholipids (PL) from preterm infants fed on conventional artificial-formula milk (C-AF; $)$, long-chain polyunsaturated fatty acid-enriched artificial formula milk (LCP-AF; O) or their own mother's milk (human milk (HM); $\nabla$ ) from birth to $35 \mathrm{~d}$ or 3 months after the initially expected date of delivery ( 3 months corrected age; $3 \mathrm{mc}$ ) expressed as absolute levels $(\mathrm{mg} / \mathrm{l} ; \mathrm{a}, \mathrm{c})$ or relative levels (mg/100 mg total fatty acid methyl esters (FAME); b, d). Values are medians and interquartile ranges represented by vertical bars for the following nos. of infants in the C-AF, LCP-AF and HM groups respectively: day 015,12 and 9 , day 716,13 and 12 ; day 1416,14 and 12 , day 2114,14 and 9 , day 2812,13 and 7 , day 359,12 and 7, $3 \mathrm{mc} 14$ and 14. Median values for LCP-AF group were significantly different from those for C-AF group (repeated-measures analysis, except for $3 \mathrm{mc}$ for which Mann Whitney $\mathrm{U}$ test was used): ${ }^{*} P<0 \cdot 01$, ${ }^{* *} P<0.001, * * * P<0.0001$. Median values for LCP-AF group were significantly different from those for HM group (changes from the values at day 0 ): $† 0$ outside $95 \% \mathrm{CI}$. For details of experimental procedures and fatty acid composition of human and artificial-formula milks, see pp. 652-654 and Table 1 and for details of subjects, see Table 2 and pp. 650-651.

$22: 6 n-3$ and $20: 4 n-6$ levels decreased to almost half the values at birth during the first week of life in both study groups. They continued to decrease in the conventional-formula group, while they stabilized in the infants fed on an LCP-enriched formula, again resulting in significantly higher levels in the latter population (22:6n-3: day $28 P<0.001$, day $35 P<$ $0.0001 ; 20: 4 n-6$ : days 28 and $35 P<0 \cdot 0001)$. At 3 months of corrected age the magnitudes of inter-group differences for relative 22:6n-3 and 20:4n-6 levels were similar to those for absolute amounts and also highly significant $(P<0.0001$ for both). At $28-35 \mathrm{~d}$ postnatal age the 22:6n-3 and 20:4n-6 status of infants fed on an LCP-enriched formula was at least 
comparable with that of preterm infants fed on their own mother's milk (for accompanying $95 \%$ CI, see Table 3 ).

Significant inter-group differences were observed also for the other fatty acids reported (for absolute and relative amounts respectively, see Tables 4 and 5). The absolute amount of $\Sigma n-6$ LCP and $\Sigma n-3$ LCP remained similar between day 0 and day 35 in the conventional-formula group, whereas their concentrations increased in the LCP-enrichedformula group, resulting in significantly higher concentrations in the latter $(\Sigma n-6 \mathrm{LCP}$ $P<0.001, \Sigma n-3$ LCP $P \leqslant 0 \cdot 0001)$. The relative levels of $\Sigma n-6$ LCP and $\Sigma n-3$ LCP declined in both formula-fed study populations, but this led to significantly lower levels in the conventional-formula group ( $P \leqslant 0.001$ for both). At 3 months of corrected postnatal age, inter-group differences were even more pronounced, both for absolute and relative $\Sigma n$ $6 \mathrm{LCP}$ and $\Sigma n-3 \mathrm{LCP}$ values ( $P<0-0001$ for all values). The relative levels of $20: 3 n-6$ and $20: 5 n-3$, similar to $20: 4 n-6$ precursors of prostaglandins and other eicosanoids, were significantly lower in the infants fed on formulas enriched with $22: 6 n-3$ and $20: 4 n-6$ until 3 months of corrected age (day 35: $20: 3 n-6 P<0.01 ; 3$ months: $20: 3 n-6 P \leqslant 0.0001$, $20: 5 n-3 P<0 \cdot 01)$. The percentage levels of the parent EFA, $18: 2 n-6$ and $18: 3 n-3$, were also significantly lower in the LCP-enriched-formula-fed infants (day 35: 18:2n-6 $P<0.01 ; 3$ months: $18: 2 n-6 P<0.0001,18: 3 n-3 P<0.001$ ).

The inter-group differences found for the $22: 6 n-3$ status were also reflected by the two indices representing the functional $22: 6 n-3$ status. Both at $35 \mathrm{~d}$ postnatal age and at 3 months corrected age, CADI values were significantly lower $(P<0.001$ and $P<0.0001$ respectively) and CASI values significantly higher $(P \leqslant 0.0001)$ in the group raised on LCPenriched formulas.

\section{Erythrocyte phospholipids}

Two RBC samples, both in the study group fed on the conventional formula, one at day 28 and one at day 35 , were lost during fatty acid analysis.

Both absolute amounts and relative levels of $22: 6 n-3$ and $20: 4 n-6$ in RBC PL decreased after birth (Fig. 2). The postnatal patterns of change for absolute amounts of $22: 6 n-3$ and $20: 4 n-6$ in the group fed on a conventional formula during the first 5 weeks of life were not significantly different from those in the LCP-enriched-formula group. However, at 3 months of corrected age the $22: 6 n-3$ concentration was significantly higher $(P<0.001)$ in the RBC PL of the infants that had received LCP-enriched formulas. Between birth and the 35 th day of life, relative levels of both 22:6n-3 (days 28 and $35 P<0.01$ ) and 20:4n-6 (day $28 P<0.001$, day $35 P<0.0001$ ) declined significantly less in the LCP-enriched-formula group than in the conventional-formula group. At the third month of corrected postnatal age these differences were even more pronounced ( $P<0 \cdot 0001$ for both). Relative 22:6n-3 and 20:4n-6 levels in LCP-enriched-formula-fed infants were comparable with those of preterm infants raised on human milk (Table 3 ).

Concentrations and relative levels of the other fatty acids studied are given in Tables 6 and 7 respectively. At 3 months corrected age, values for $\Sigma n-6 \mathrm{LCP}(\mathrm{mg} / 100 \mathrm{mg}$ total fatty acids $P<0.001)$ and $\Sigma n-3 \mathrm{LCP}(\mathrm{mg} / 1 P<0.01, \mathrm{mg} / 100 \mathrm{mg}$ total fatty acids $P<0.0001)$ were significantly higher in the infants raised on the LCP-enriched formulas than in the infants given the conventional formulas. At the same time, values for the parent EFA $18: 2 n-6(\mathrm{mg} / 1 P \leqslant 0.01, \mathrm{mg} / 100 \mathrm{mg}$ total fatty acids $P<0.0001)$ and $18: 3 n-3(\mathrm{mg} / 1 P<$ $0.001, \mathrm{mg} / 100 \mathrm{mg}$ total fatty acids $P \leqslant 0.001)$ and for $20: 3 n-6(\mathrm{mg} / 1 P<0.001, \mathrm{mg} / 100 \mathrm{mg}$ total fatty acids $P<0.0001)$ and $20: 5 n-3(\mathrm{mg} / 100 \mathrm{mg}$ total fatty acids $P<0.01)$ were significantly lower in the LCP-enriched-formula group.

The two indices calculated confirmed the observed inter-group difference in $22: 6 n-3$ status, with lower values for the CADI ( 3 months $P<0.0001)$ and higher values for the 
Table 3. 95\% CI for differences between long-chain polyunsaturated fatty acid (LCP)enriched artificial-formula-milk (LCP-AF)-fed and human-milk $(H M)$-fed groups of preterm infants ${ }^{*}+$

\begin{tabular}{|c|c|c|}
\hline Fatty acid & $\begin{array}{l}\text { Day } 28 \text {-day } 0_{\mathrm{LCP}-\mathrm{AF}}- \\
\text { Day } 28 \text {-day } 0_{\mathrm{HM}}\end{array}$ & $\begin{array}{c}\text { Day 35-day } 0_{\mathrm{LCP}-\mathrm{AF}}- \\
\text { Day 35-day } 0_{\mathrm{HM}}\end{array}$ \\
\hline \multicolumn{3}{|c|}{$\begin{array}{l}\text { Plasma phospholipids: } \\
\mathrm{mg} / 1\end{array}$} \\
\hline $\begin{array}{l}22: 6 n-3 \\
20: 4 n-6\end{array}$ & $\begin{array}{l}-8 \cdot 12-3 \cdot 72 \\
-2 \cdot 89-34 \cdot 31\end{array}$ & $\begin{array}{l}-3.92-6.92 \\
3.51-41.81\end{array}$ \\
\hline \multicolumn{3}{|l|}{$\mathrm{mg} / 100 \mathrm{mg}$} \\
\hline $22: 6 n-3$ & $-0.97-0.75$ & $-0 \cdot 62-1 \cdot 10$ \\
\hline $20: 4 n-6$ & $-2 \cdot 79-0.77$ & $-2 \cdot 12-1 \cdot 36$ \\
\hline \multicolumn{3}{|c|}{$\begin{array}{l}\text { Erythrocyte phospholipids: } \\
\mathrm{mg} / 1\end{array}$} \\
\hline $22: 6 n-3$ & $-9 \cdot 59-4 \cdot 79$ & $-18 \cdot 24-1 \cdot 10$ \\
\hline $20: 4 n-6$ & $-30 \cdot 45-31 \cdot 61$ & $-67.54-6.08$ \\
\hline \multicolumn{3}{|l|}{$\mathrm{mg} / 100 \mathrm{mg}$} \\
\hline $22: 6 n-3$ & $-0.54-0.04$ & $-0.51-0.19$ \\
\hline $20: 4 n-6$ & $-1.07-1 \cdot 17$ & $-0.91-1.33$ \\
\hline
\end{tabular}

* For details of experimental procedures and fatty acid composition of human and artificial-formula milks, see pp. $652-654$ and Table 1.

$\dagger$ For details of subjects, see Table 2 and pp. 650-651.

CASI (day $35 P \leqslant 0.001,3$ months $P \leqslant 0.0001$ ) in the RBC PL of infants receiving LCPenriched formulas.

\section{DISCUSSION}

The present study is, to our knowledge, the first to report on the effects of long-term feeding of artificial formulas enriched with both $22: 6 n-3$ and $20: 4 n-6$. Its results show that adding these two major LCP to formulas in balanced ratios, and in amounts comparable with those found in preterm human milk, successfully raises both the $22: 6 n-3$ and $20: 4 n-6$ status of preterm-formula-fed infants to values found in plasma and RBC PL of preterm infants fed on human milk. Inter-group differences in the $22: 6 n-3$ status were also reflected by the two indices of the functional $22: 6 n-3$ status, with lower CADI values and higher CASI values in the infants raised on LCP-enriched formulas.

Results of three studies that evaluated the effects of short-term feeding of an $n-3$ and n-6 LCP-enriched formula on the LCP status of preterm infants are available for comparison. Koletzko et al. (1989) reported that $17 \mathrm{~d}$ (days 4-21) of feeding an artificial formula containing $22: 6 n-3$ and $20: 4 n-6$ in levels half those present in human milk resulted in plasma lipid LCP levels that were higher than those of infants fed on a conventional formula, but were still substantially lower than those of infants raised on human milk. In a more recent study by Clandinin et al. (1992), preterm infants fed for 4 weeks (1-5 weeks) on an artificial formula which contained all n-3 and n-6 LCP within the range characteristic of human milk had plasma PL-associated LCP concentrations similar to those of infants fed on human milk. LCP levels in RBC PC and phosphatidylethanolamine (PE) were also evaluated, but reported not to be affected by dietary LCP supply. Preliminary results from a study by Carnielli et al. (1994), in which the LCP-enriched formula contained $0.60 \mathrm{mg}$

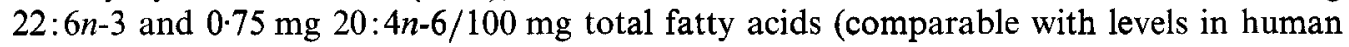
colostrum), also indicated similar plasma PL LCP levels in LCP-enriched-formula-fed and human-milk-fed infants at 4 weeks of age.

Enhancing the dietary intake of the parent EFA of the $n-3$ series, $18: 3 n-3$, has been 


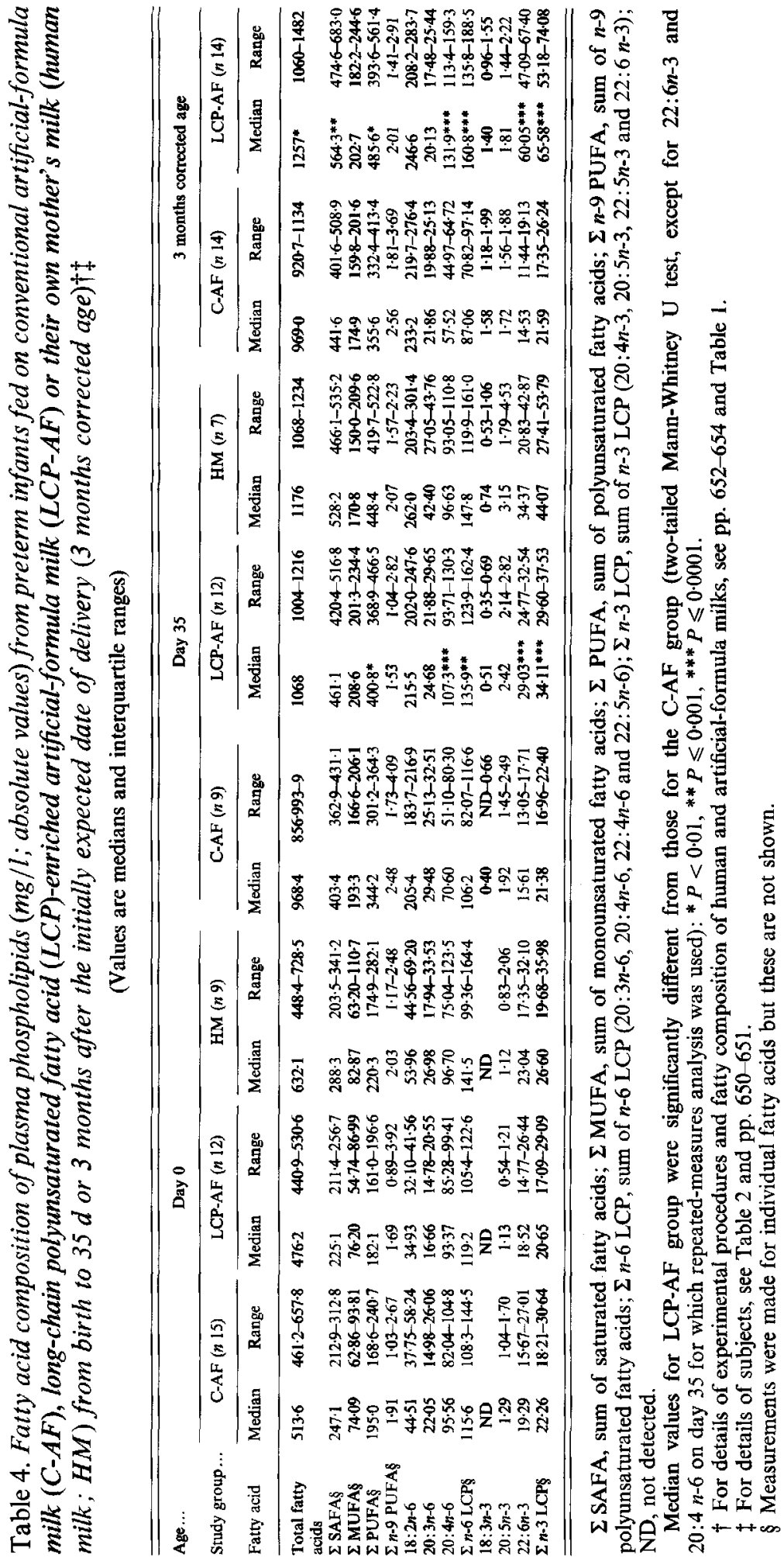




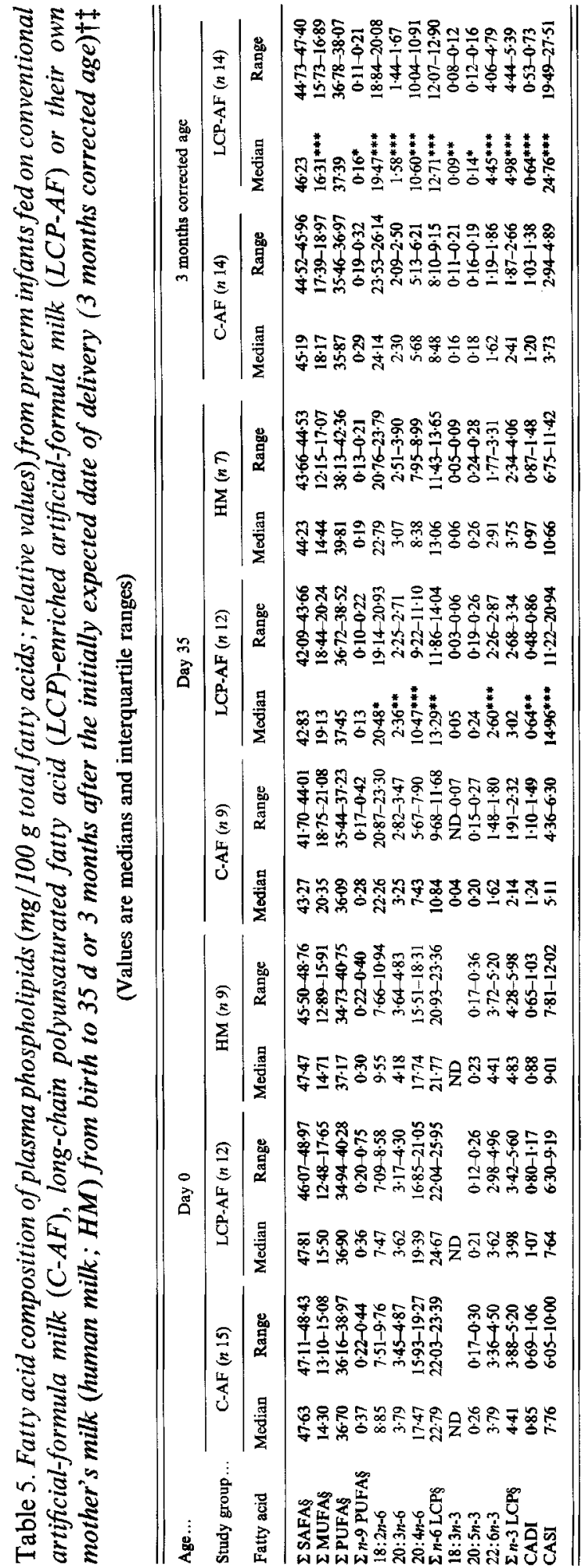

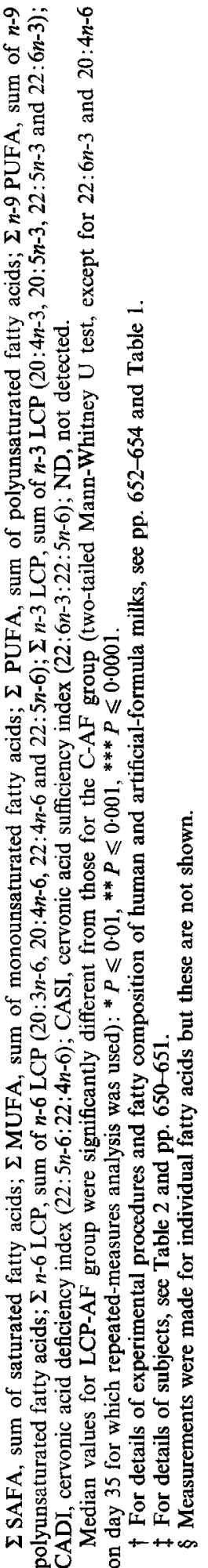



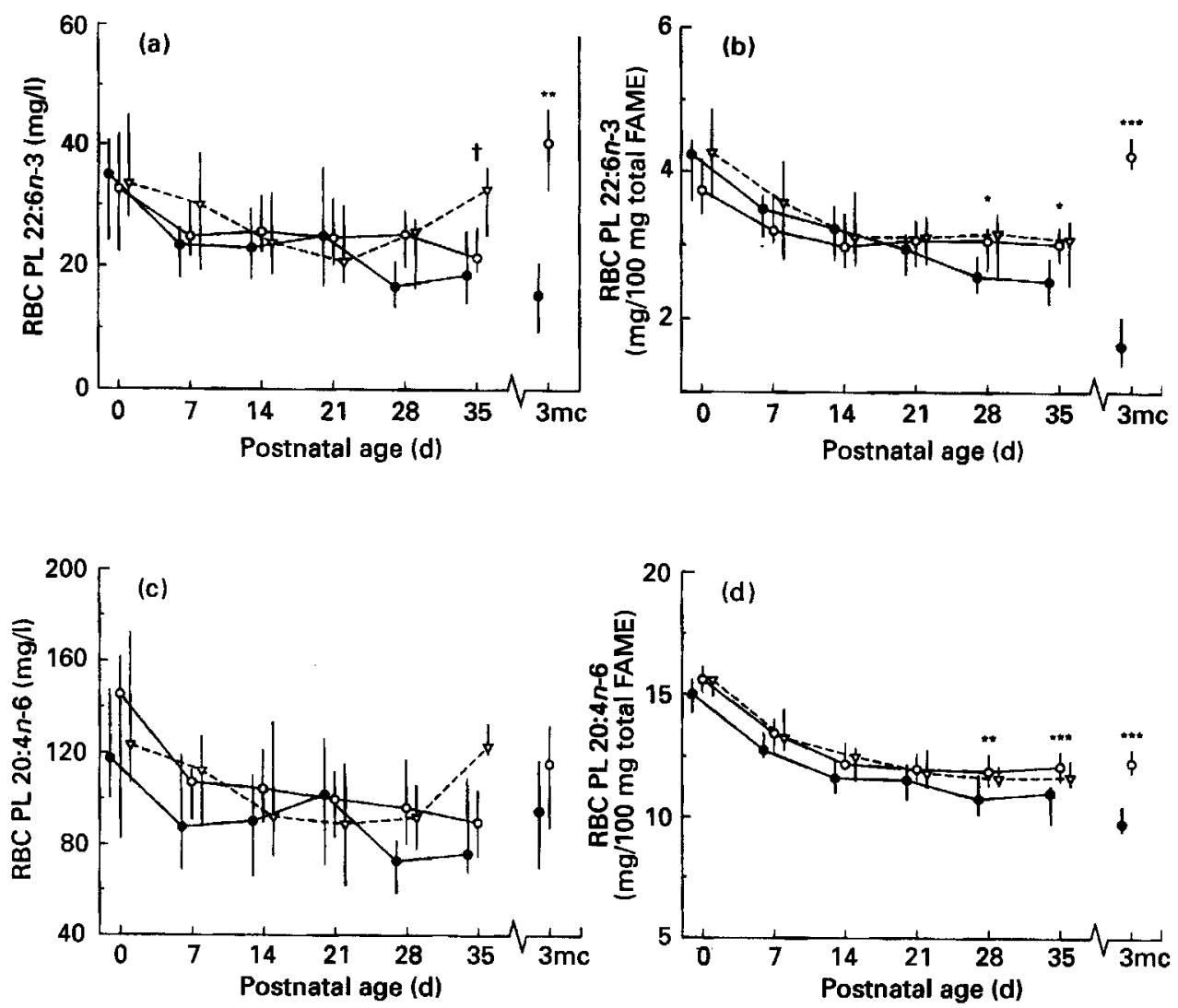

Fig. 2. Fatty acid $22: 6 n-3$ and $20: 4 n-6$ levels in erythrocyte (RBC) phospholipids (PL) from preterm infants fed on conventional artificial-formula milk (C-AF; $)$, long-chain polyunsaturated fatty acid-enriched artificialformula milk (LCP-AF; O) or their own mother's milk (human milk (HM); $\nabla$ ) from birth to $35 \mathrm{~d}$ or $3 \mathrm{months}$ after the initially expected date of delivery ( 3 months corrected age; $3 \mathrm{mc}$ ) expressed as absolute values (mg/1; a, c) or as relative values ( $\mathrm{mg} / 100 \mathrm{mg}$ total fatty acid methyl esters (FAME); b, d). Values are medians and interquartile ranges represented by vertical bars for the following nos. of infants in the C-AF, LCP-AF and HM groups respectively: day 015,12 and 9 , day 716,13 and 12 , day 1416,14 and 12 , day 2114,14 and 9 , day 28 11,13 and 7, day 35 8, 12 and 7, 3 mc 14 and 14. Median values for the LCP-AF group were significantly different from those for C-AF group (repeated measures analysis, except for $3 \mathrm{mc}$ for which Mann Whitney $U$ test was used): ${ }^{*} P<0.01,{ }^{* *} P<0.001, * * * P<0.0001$. Median values for LCP-AF group were significantly different from those for HM group (changes from the values at day 0 ): $† 0$ outside $95 \% \mathrm{CI}$. For details of experimental procedures and fatty acid composition of human and artificial-formula milks, see pp. 652-654 and Table 1 and for details of subjects, see Table 2 and pp. $650-651$.

suggested to be equally effective in increasing the $n-3$ LCP status as adding $n-3$ LCP to formulas. This view was based on the results of two short-term (4-5 weeks) feeding trials, in which $\mathrm{RBC} 22: 6 n-3$ levels of preterm infants consuming formulas containing $>2.0 \mathrm{mg}$ $18: 3 n-3 / 100 \mathrm{mg}$ total fatty acids were reported not to differ from those of infants fed on human milk (Innis et al. 1990; Uauy et al. 1990). However, longer-term studies have quite clearly demonstrated that even higher intakes of $18: 3 n-3$ (up to $4.8 \mathrm{mg} / 100 \mathrm{mg}$ total fatty acids, with a $18: 2 n-6: 18: 3 n-3$ as low as 6.4 ) cannot prevent $n-3$ LCP declines in formulafed preterm infants (Carlson et al. 1991; Hoffman \& Uauy, 1992). The artificial formulas used in the present study were designed to contain the parent EFA in amounts present in human milk, resulting in a maximum $18: 2 n-6: 18: 3 n-3$ of $13 \cdot 0$.

At 3 months after the initially expected date of delivery, both the $22: 6 n-3$ and $20: 4 n-6$ status were considerably higher in the plasma and RBC PL of infants that had been fed on 


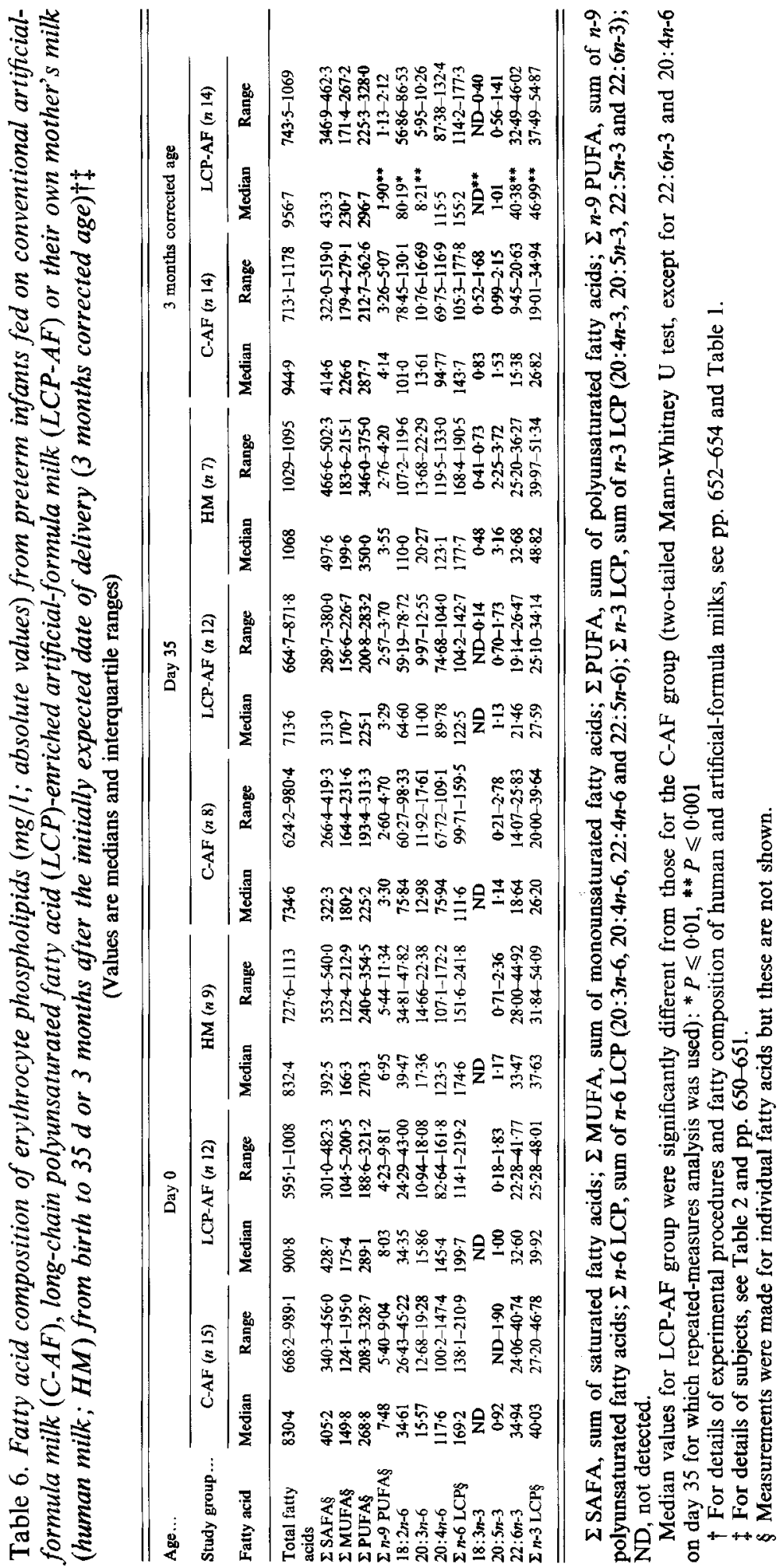


LCP-ENRICHED FORMULAS AND PRETERM LCP STATUS

663

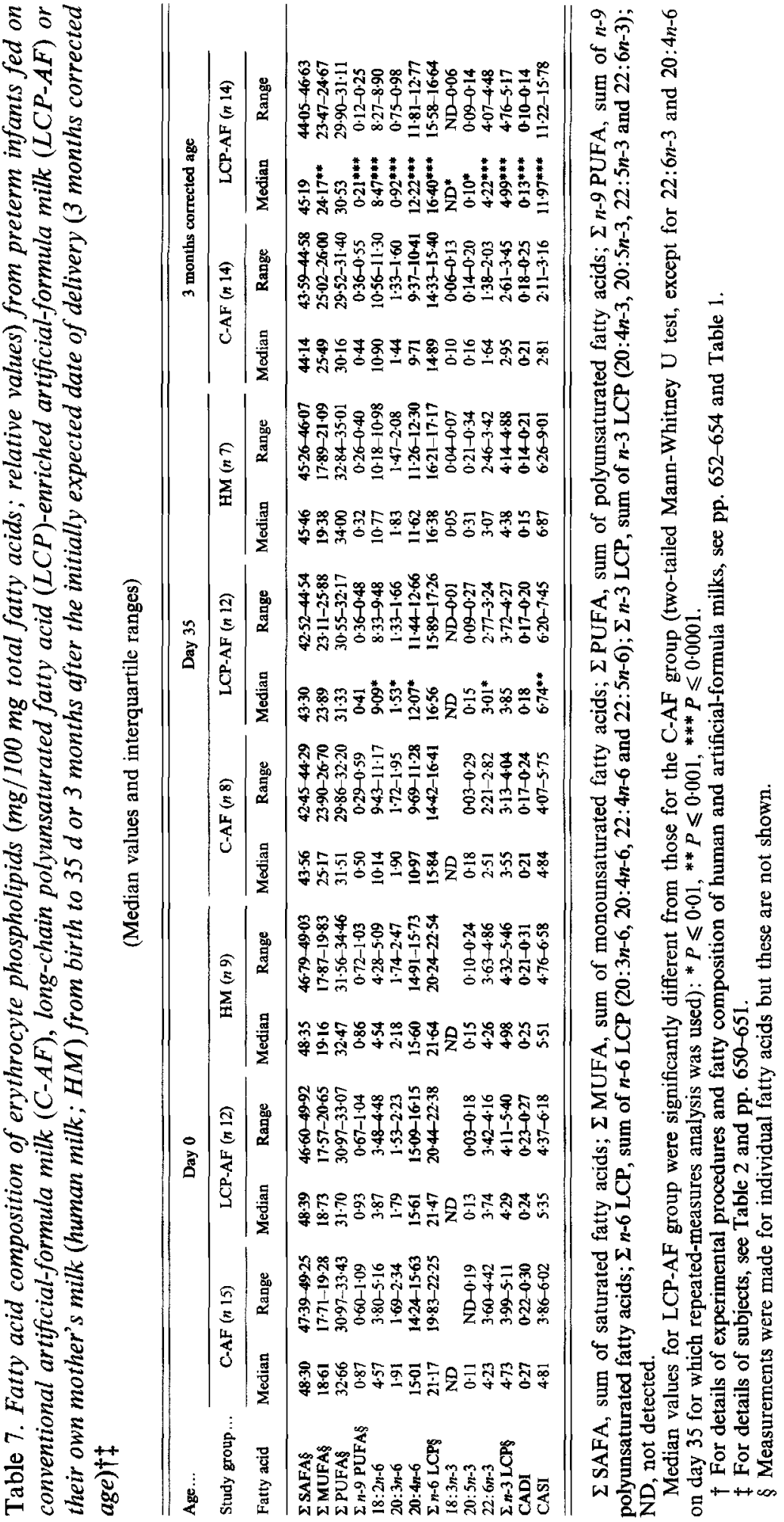


artificial formulas enriched with these LCP than in those that had received conventional formulas. Unfortunately at this age, the values of the LCP-enriched-formula group could not be compared with those of the preterm infants fed on human milk, since the majority of these infants had to be excluded from further follow-up due to the limited amounts of human milk they actually received. However, the plasma levels of $22: 6 n-3$ and $20: 4 n-6$ in our LCP-enriched-formula group were similar to, and RBC levels somewhat lower than, those recently reported by Luukkainen et al. (1995) for ten preterm infants which were fully breast-fed until 6 months postnatal age. This strongly suggests that the $22: 6 n-3$ and 20:4n-6 levels measured in the infants fed on LCP-enriched formulas are within their physiological ranges. Carlson et al. (1991), at approximately 3 months corrected age, observed 22:6n-3 values in plasma and RBC PC and PE of preterm infants fed on $n-3$ LCPenriched formulas which were only twice as high as those in infants fed on conventional formulas. The $18: 2 n-6: 18: 3 n-3$ present in these conventional formulas, however, were smaller (6.4-6.9 compared with $9 \cdot 1-11 \cdot 9)$, and the $18: 3 n-3$ contents higher $(3 \cdot 0-4 \cdot 8$ compared with $1 \cdot 2-1.4 \mathrm{mg} / 100 \mathrm{mg}$ total fatty acids) than those in ours, which may account for the somewhat smaller inter-group differences than in the present study.

After 28-35 $\mathrm{d}$ of life the $22: 6 n-3$ and $20: 4 n-6$ status of the infants fed on a preterm formula containing these LCP in amounts typical for human milk was indeed comparable with that of infants receiving actual human milk. However, during the study period the total enteral intake of the human-milk-fed group, on average, consisted of only $893 \mathrm{ml}$ human milk/ 1 intake, while the LCP-enriched-formula group consumed almost exclusively their particular study formula. This apparently higher efficiency of human milk in maintaining certain LCP levels, when compared with the LCP-enriched artificial formula, is possibly related to the presence of human-milk bile-salt-stimulated lipase, which is not only known to be of major importance for overall triacylglycerol digestion (Hernell \& Bläckberg, 1991), but may also play a particular role in the release of LCP during this process (Hernell et al. 1993; Chen et al. 1994).

In the present study a diet-induced decrease in $20: 4 n-6$, which was reported after supplying only additional $n$-3 LCP (Carlson et al. 1991; Hoffman \& Uauy, 1992), was not observed. Preliminary data by Carlson et al. $(1992 b)$ indicated that reducing the amount of $20: 5 n-3$ added to the formula ( 0.06 instead of $0.3 \mathrm{mg} / 100 \mathrm{mg}$ total fatty acids) prevents this lowering of the 20:4n-6 status. However, considering the presence of high levels of 20:4n-6 in neural tissue and the potential influence of this $n-6$ LCP on postnatal growth, raising the 20:4n-6 status of formula-fed preterm infants to that of infants receiving human milk may be preferable. To achieve this, adding preformed $20: 4 n-6$ to the formulas appears to be necessary.

The use of an LCP-enriched formula not only resulted in higher $22: 6 n-3$ and $20: 4 n-6$ values, but also in significantly lower blood levels of $18: 2 n-6$ in the supplemented formula group, when compared with the infants fed on the conventional formulas. This relatively short-term effect was also found in other LCP-supplementation studies (Clandinin et al. 1992; Carnielli et al. 1994). The decreased 18:2n-6 values may reflect a competition between this parent EFA and the supplemented $n-3$ and $n-6$ LCP for incorporation into blood PL.

Effects of enhancing the LCP content of artificial formulas were not only detected in plasma PL, but also in RBC PL. The assumption that changes observed in the fatty acid profile of the $\mathrm{RBC}$ membrane reflect changes occurring in the fatty acid composition of the brain (Carlson et al. 1986 b; Neuringer et al. 1986) has been subject of debate (Innis, 1992). However, for $22: 6 n-3$, recent studies demonstrated that breast-fed infants have significantly higher levels of this major $n$-3 LCP in their cerebral cortex lipids than formula-fed infants (Farquharson et al. 1992; Neuringer, 1993; Makrides et al. 1994), and that these levels are significantly related to those in RBC (Makrides et al. 1994). The findings of these studies 
are supplemented by those of the increasing number of studies that report significant influences of the dietary LCP supply, and the resultant LCP status, on several variables of brain and visual function (Uauy, 1990; Uauy et al. 1990; Birch et al. 1992 a, b; Carlson et al. $1993 \mathrm{~b}$ ). However, all these studies have focused entirely on the dietary intake of $n$ 3 LCP. Further studies in preterm infants are needed to evaluate the potential functional consequences of enhancing the dietary 20:4n-6 intake, other than achieving better growth.

In conclusion, adding $22: 6 n-3$ and $20: 4 n-6$ to artificial formulas in balanced ratios, and in amounts similar to those found in preterm human milk, raises both the $22: 6 n-3$ and the 20:4n-6 status of formula-fed preterm infants to values reported for human-milk-fed preterm infants. Additional studies are necessary to evaluate the potentially favourable effects of feeding formulas enriched with both $n-3$ and n-6 LCP on the neurodevelopmental outcome of preterm infants.

The authors gratefully acknowledge the financial support from Nutricia, Zoetermeer, The Netherlands and the skilled assistance obtained from Mrs H. Aydeniz (preparation of plasma and RBC samples) and the Analytical Biochemical Laboratory in Assen, The Netherlands (fatty acid analysis of blood samples). They also wish to express their appreciation for the help obtained from Mrs M.-J. Slangen, Children's Laboratory of the University Hospital Maastricht (neonatal blood sampling), the staff and nursing personnel of the Departments of Neonatology of the University Hospital Maastricht, the Saint Joseph Hospital in Kerkrade and the De Wever Hospital in Heerlen, The Netherlands (practical assistance) and Miss E. E. Zeijdner (practical assistance).

\section{REFERENCES}

Birch, E. E., Birch, D. G., Hoffman, D. R. \& Uauy, R. (1992a). Retinal development in a very low birth weight infants fed diets differing in omega-3 fatty acids. Investigations in Ophthalmology and Visual Science 33, 2365-3276.

Birch, E. E., Birch, D. G., Hoffman, D. R. \& Uauy, R. (1992b). Dietary essential fatty acid supply and visual acuity development. Investigations in Ophthalmology and Visual Science 33, 3242-3253.

Bligh, E. G. \& Dyer, W. J. (1959). A rapid method for total lipid extraction and purification. Canadian Journal of Biochemistry and Physiology 37, 11-17.

Carlson, S. E., Carver, J. D. \& House, S. A. (1986a). High fat diets varying in ratios of polyunsaturated to saturated fatty acid and linoleic to linolenic acid: a comparison of rat neural and red cell membrane phospholipids. Journal of Nutrition 116, 718-725.

Carlson, S. E., Cooke, R. J., Rhodes, P. G., Peeples, J. M., Werkman, S. H. \& Tolley, E. A. (1991). Long-term feeding of formulas high in linolenic acid and marine oil to very low birth weight infants: phospholipid fatty acids. Pediatric Research 30, 404-412.

Carlson, S. E., Cooke, R. J., Werkman, S. H. \& Tolley, E. A. (1992b). First year growth of preterm infants fed standard compared to marine oil $n-3$ supplemented formula. Lipids 27, 901-907.

Carlson, S. E., Peeples, J. M., Cooke, R. J. \& Werkman, S. H. (1992b). Effects of docosahexanoate (DHA, $22: 6 n-3)$ supplementation of preterm (PT) infants on arachidonate (AA, 20:4n-6) and DHA status. Pediatric Research 31, 286A.

Carlson, S. E., Rhodes, P. G. \& Ferguson, M. G. (1986a). Docosahexaenoic acid status of preterm infants at birth and following feeding with human milk or formula. American Journal of Clinical Nutrition 44, 798-804.

Carlson, S. E., Rhodes, P. G., Rao, V. S. \& Goldgar, D. E. (1987). Effect of fish-oil supplementation in the $n-3$ fatty acid content of red blood cell membranes in preterm infants. Pediatric Research 21, 507-510.

Carlson, S. E., Werkman, S. H., Peeples, J. M., Cooke, R. J. \& Tolley, E. A. (1993a). Arachidonic acid status correlates with first year growth in preterm infants. Proceedings of the National Academy of Sciences, USA $\mathbf{9 0}$, 1073-1077.

Carlson, S. E., Werkman, S. H., Rhodes, Ph. G. \& Tolley, E. A. (1993b). Visual-acuity development in healthy preterm infants: effect of marine-oil supplementation. American Journal of Clinical Nutrition 58, 35-42.

Carnielli, V. P., Pederzini, F., Luijendijk, I. H. T., Bomaars, W. E. M., Boerlage, A., Degenhart, H. J., Pedrotti, D. \& Sauer, P. J. J. (1994). Long chain polyunsaturated fatty acids (LCP) in low birth weight formula at levels found in human colostrum. Pediatric Research 35, 309A.

Chambaz, J., Ravel, D., Manier, M.-C., Pepin, D., Mulliez, N. \& Bereziat, G. (1985). Essential fatty acid interconversion in the human fetal liver. Biology of the Neonate 47, 136-140.

Chen, Q., Bläckberg, L., Nilsson, A., Sternby, B. \& Hernell, O. (1994). Digestion of triacylglycerols containing 
long-chain polyenoic fatty acids in vitro by colipase-dependent pancreatic lipase and human milk bile saltstimulated lipase. Biochimica et Biophysica Acta 1210, 239-243.

Clandinin, M. T., Chappell, J. E., Heim, T., Swyer, P. R. \& Chance, G. W. (1981 a). Fatty acid accretion in fetal and nconatal liver: implications for fatty acid requirements. Early Human Development 5, 7-14.

Clandinin, M. T., Chappell, J. E., Heim, T., Swyer, P. R. \& Chance, G. W. (1981b). Fatty acid utilization in perinatal de novo synthesis of tissues. Early Human Development 5, 355-366.

Clandinin, M. T., Chappell, J. E., Leong, S., Heim, T., Swyer, P. R. \& Chance, G. W. (1980a). Intrauterine fatty acid accretion rates in human brain: implications for fatty acid requirements. Early Human Development 4 , 121-129.

Clandinin, M. T., Chappell, J. E., Leong, S., Heim, T., Swyer, P. R. \& Chance, G. W. (1980b). Extrauterine fatty acid accretion in infant brain: implications for fatty acid requirements. Early Human Development 4, 131-138.

Clandinin, M. T., Parrott, A., Van Aerde, J. E., Hervada, A. R. \& Lien, E. (1992). Feeding preterm infants a formula containing $\mathrm{C}_{20}$ and $\mathrm{C}_{22}$ fatty acids simulates plasma phospholipid fatty acid composition of infants fed human milk. Early Human Development 31, 41-51.

Dallal, G. E. (1988). DESIGN: A supplementary Module for Systat and Sysgraph. Evanston, IL: SYSTAT, Inc. Dixon, W. J. (1992). BMDP Statistical Software Manual: To Accompany the 7.0 Software Release, vol. 2, pp. 1311-1352. Berkeley, CA: University of California Press.

Dubowitz, L. M. S., Dubowitz, V. \& Goldberg, C. (1970). Clinical assessment of gestational age in the newborn infant. Journal of Pediatrics 77, 1-10.

Farquharson, J., Cockburn, F., Patrick, W. A., Jamieson, E. C. \& Logan, R. W. (1992). Infant cerebral cortex fatty acid composition and diet. Lancet 340, 810-813.

Fliesler, S. J. \& Anderson, R. E. (1983). Chemistry and metabolism of lipids in the vertebrate retina. Progress in Lipid Research 22, 79-131.

Foreman-van Drongelen, M. M. H. P., van Houwelingen, A. C., Kester, A. D. M., de Jong, A. E. P., Blanco, C. E., Hasaart, T. H. M. \& Hornstra, G. $(1995 a)$. Long chain polyene status of preterm infants with regard to the fatty acid composition of their diet: comparison between absolute and relative fatty acid amounts in plasma and red blood cell phospholipids. British Journal of Nutrition 73, 405-422.

Foreman-van Drongelen, M. M. H. P., van Houwelingen, A. C., Kester, A. D. M., Hasaart, T. H. M., Blanco, C. E. \& Hornstra, G. $(1995 \mathrm{~b}$ ). Long chain polyunsaturated fatty acids in preterm infants: status at birth and its influence on postnatal levels. Journal of Pediatrics 126, 611-618.

Hernell, O. \& Bläckberg, L. (1991). Digestion and absorption of human milk lipids. In Encyclopedia of Human Biology, vol. 3, pp. 47-56 [R. Dulbecco, editor]. New York: Academic Press.

Hernell, O., Bläckberg, L., Chen, Q., Sternby, B. \& Nilsson, A. (1993). Does the bile salt-stimulated lipase of human milk have a role in the use of the milk long-chain polyunsaturated fatty acids? Journal of Gastroenterology and Nutrition 16, 426-431.

Hoffman, D. R. \& Uauy, R. (1992). Essentiality of dietary $\omega 3$ fatty acids for premature infants: plasma and red blood cell fatty acid composition. Lipids 27, 886-895.

Holman, R. T. (1977). The deficiency of essential fatty acids. In Polyunsaturated Fatty Acids, vol. 4, pp. 163-182 [W. Kunau and R. T. Holman, editors]. Champaign, IL: American Oil Chemists Society.

Holman, R. T. (1986). Control of polyunsaturated fatty acids in tissue lipids. Journal of the American College of Nutrition 5, 183-211.

Innis, S. M. (1992). Plasma and red blood cell fatty acid values as indexes of essential fatty acids in the developing organs of infants fed with milk or formulas. Journal of Pediatrics 120, S78-S86.

Innis, S. M., Foote, K. D., MacKinnon, M. J. \& King, D. J. (1990). Plasma and red cell fatty acids of low birthweight infants fed their mothers expressed breast milk or preterm infant formula. American Journal of Clinical Nutrition 51, 994-1000.

Jennrich, R. 1. \& Schluchter, M. D. (1986). Unbalanced repeated-measures models with structured covariance matrices. Biometrics 42, 805-820.

Jensen, R. G., Ferris, A. M. \& Lammi-Keefe, C. J. (1992). Lipids in human milk and infant formulas. Annual Review of Nutrition 12, 417-441.

Jensen, R. G., Hagerty, M. M. \& McMahon, K. E. (1978). Lipids of human milk and infant formulas: a review. American Journal of Clinical Nutrition 31, 990-1016.

Kloosterman, G. J. (1970). On intrauterine growth, the significance of prenatal care. International Journal of Gynaecology and Obstetrics 8, 895-912.

Koletzko, B., Schmidt, E., Bremer, H. J., Haug, M. \& Harzer, G. (1989). Effects of dietary long chain polyunsaturated fatty acids on the essential fatty acid status of premature infants. European Journal of Pediatrics 148, 669-675.

Lammi-Keefe, C. J. \& Jensen, R. G. (1984). Lipids in human milk: a review. 2: Composition and fat-soluble vitamins. Journal of Pediatric Gastroenterology and Nutrition 3, 172-198.

Liu, C.-C. F., Carlson, S. E., Rhodes, P. G., Rao, V. S. \& Meydrech, E. F. (1987). Increase in plasma phospholipid docosahexaenoic and eicosapentaenoic acids as a reflection of their intake and mode of administration. Pediatric Research 22, 292-296.

Luukkainen, P., Salo, M. K., Janas, M. \& Nikkari, T. (1995). Fatty acid composition of plasma and red blood cell phospholipids in preterm infants from 2 weeks to 6 months postpartum. Journal of Pediatric Gastroenterology and Nutrition 20, 310-315. 
Makrides, M., Neumann, M. A., Byard, R. W., Simmer, K. \& Gibson, R. A. (1994). Fatty acid composition of brain, retina, and erythrocytes in breast- and formula-fed infants. American Journal of Clinical Nutrition $\mathbf{6 0}$, 189-194.

Martinez, M. (1992). Tissue concentration of polyunsaturated fatty acids during early human development. Journal of Pediatrics 120, S129-S138.

Martinez, M., Ballabriga, A. \& Gil-Gibernou, J. J. (1988). Lipids of the developing human retina: I. Total fatty acids, plasmalogens, and fatty acid composition of ethanolamine and choline phosphoglycerides. Journal of Neuroscience Research 20, 484-490.

Martinez, M., Conde, C. \& Ballabriga, A. (1974). Some chemical aspects of human brain development. II. Phosphoglyceride fatty acids. Pediatric Research 8, 93-102.

Neuringer, M. (1993). Cerebral cortex docosahexaenoic acid is lower in formula-fed than in breast-fed infants. Nutrition Reviews 51, 238-241.

Neuringer, M., Connor, W. E., Lin, D. S., Barstad, L. \& Luck, S. (1986). Biochemical and functional effects of prenatal and postnatal $\mathrm{w} 3$ fatty acid deficiency on retina and brain in rhesus monkeys. Proceedings of the National Academy of Sciences, USA 83, 4021-4025.

NEVO Foundation (1993). Nederlandse voedingsmiddelentabel 1993 (Dutch Food Composition Table 1993). The Hague, The Netherlands: Voorlichtingsbureau voor de Voeding.

Pita, M. L., Fernández, M. R., De-Lucchi, C., Medina, A., Martínez-Valverde, A., Uauy, R. \& Gil, A. (1988). Changes in the fatty acids pattern of red blood cell phospholipids induced by type of milk, dietary nucleotide supplementation, and postnatal age in preterm infants. Journal of Pediatric Gastroenterology and Nutrition 7 , $740-747$

Sastry, P. S. (1985). Lipids of nervous tissue: composition and metabolism. Progress in Lipid Research 24, 69-176.

Svennerholm, L. (1968). Distribution and fatty acid composition of phosphoglycerides in normal human brain. Journal of Lipid Research 9, 570-579.

Uauy, R. (1990). Are w-3 fatty acids required for normal eye and brain development in the human? Journal of Pediatric Gastroenterology and Nutrition 11, 296-300.

Uauy, R. D., Birch, D. G., Birch, E. E., Tyson, J. E. \& Hoffman, D. R. (1990). Effect of dietary omega-3 fatty acids on retinal function of very-low-birth-weight neonates. Pediatric Research 28, 485-492. 